\title{
Soluble organic additive effects on stress development during drying of calcium carbonate suspensions
}

\author{
Pär Wedin ${ }^{\mathrm{a}}$, Jennifer A. Lewis ${ }^{\mathrm{b}}$, Lennart Bergström ${ }^{\mathrm{c}, *}$ \\ ${ }^{a}$ YKI, Institute for Surface Chemistry, P.O. Box 5607, SE-11486 Stockholm, Sweden \\ ${ }^{\mathrm{b}}$ Department of Materials Science and Engineering, University of Illinois, Urbana, IL 6180, USA \\ ${ }^{c}$ Department of Physical, Inorganic and Structural Chemistry, Stockholm University, SE-10691 Stockholm, Sweden
}

Received 15 December 2004; accepted 3 April 2005

Available online 27 April 2005

\begin{abstract}
The effect of polymer, plasticizer, and surfactant additives on stress development during drying of calcium carbonate particulate coatings was studied using a controlled-environment apparatus that simultaneously monitors drying stress, weight loss, and relative humidity. We found that the calcium carbonate coatings display a drying stress evolution typical of granular films, which is characterized by a sharp capillary-induced stress rise followed by a rapid stress relaxation. The addition of a soluble polymer to the $\mathrm{CaCO}_{3}$ suspension resulted in a two-stage stress evolution process. The initial stress rise stems from capillary-pressure-induced stresses within the film, while the second, larger stress rise occurs due to solidification and shrinkage of the polymeric species. Measurements on the corresponding pure polymer solutions established a clear correlation between the magnitude of residual stress in both the polymer and $\mathrm{CaCO}_{3}-$ polymer films to the physical properties of the polymer phase, i.e. its glass transition temperature, $T_{\mathrm{g}}$, and Young's modulus. The addition of small organic molecules can reduce the residual stress observed in the $\mathrm{CaCO}_{3}$-polymer films; e.g., glycerol, which acts as a plasticizer, reduces the drying stress by lowering $T_{\mathrm{g}}$, while surfactant additions reduce the surface tension of the liquid phase, and, hence, the magnitude of the capillary pressure within the film.
\end{abstract}

(C) 2005 Elsevier Inc. All rights reserved.

Keywords: Drying; $\mathrm{CaCO}_{3}$; Coating; Suspension; Stress; Plasticizer; Polymer; Surfactant; CMC; PVA; EHEC

\section{Introduction}

The formation of thin films and coatings by drying colloidal dispersions on a substrate is a subject of both technological and scientific interest. This approach is used to create thin coatings on paper [1,2], to coat various surfaces with a protective or decorative paint $[3,4]$, or to fabricate ceramic substrates and multilayer devices [5,6]. Of particular interest is understanding and controlling the stresses that develop during drying of granular films to alleviate crack formation, warping, as well as dimensional changes that can occur in the coating when released from the underlying substrate

\footnotetext{
* Corresponding author.

E-mail address: lennartb@inorg.su.se (L. Bergström).
}

$[7,8]$. Recent experimental and theoretical work has investigated the stress evolution of colloidal films and shown that the compressive stress exerted on the particle network during drying originates from the capillary pressure induced by the liquid menisci between the particles [7-13]. Routh and Russel described the stress and strain evolution of a drying film based on a model of viscoelastic deformation of particle network, which is of particular relevance for latex film formation [13]. Tirumkudulu and Russel expanded this model by accounting for the inhomogeneities related to the propagating drying fronts and a spatially varying evaporation rate [12]. Comparison with cantilever stress measurements during drying of model dispersions showed that this model is able to capture to essential features of the stress evolution of both soft (film-forming) and hard (nonfilm-forming) particles [12]. 
Colloidal dispersions used in paper coatings, paints, and ceramic processing are often quite complex. They can contain several organic additives, including soluble polymers (or latex binders), plasticizers, and surfactants. Paper coating formulations, for example, rely on soluble polymers and small organic molecules to control the viscosity of the continuous phase during the critical drying and dewatering stage, when the concentrated dispersion has been applied onto the paper sheet in a high-speed process [14]. Soluble polymers are also frequently used as dispersants and binders in the manufacture of ceramic green bodies or as thickeners in paint formulations, whereas surfactants are utilized to disperse pigment and latex particles in paints or to reduce the liquid surface tension in coatings applied by spraying processes.

The presence of soluble polymers can strongly influence the stress evolution observed during drying of colloidal films. Lewis and co-workers showed that substantial residual stresses develop in non-aqueous colloidal films containing poly(vinyl butyral) [6]. More recently, in work relevant to paper coatings, Wedin et al. [9] showed that the addition of carboxymethyl cellulose (CMC) to aqueous calcium carbonate suspensions dominated the stress evolution during drying yielding films with large residual stress values. The origin of residual stresses in such films is distinctly different from the capillary-induced drying stress, whose onset coincides with the point where the particle network ceases to consolidate, i.e., when the liquid-vapor interface first begins to recede into the coating $[6,9,10]$. The strong similarity between the drying stress behavior of binary particle-polymer and pure polymer films suggests that large residual stresses can be attributed to the solidification and shrinkage of the polymer phase as liquid evaporation occurs [6,9]. Yet in recent work on the stress evolution of starch-containing calcium carbonate suspensions, Laudone et al. $[15,16]$ attributed the large increase in the observed drying stress upon starch additions solely to an enhanced capillary pressure due to tighter particle packing and, hence, smaller pore sizes within the film.

Here, we aim to investigate how soluble polymers and other organic additives of relevance in paper coating formulations affect the stress evolution of calcium carbonate $\left(\mathrm{CaCO}_{3}\right)$ suspensions as well as to explore routes for reducing residual stresses in these granular films. Specifically, we have studied the effects of four water-soluble polymers: (1) CMC, (2) an acrylate-based alkali-swellable thickener (ASE), (3) polyvinyl alcohol (PVA), and (4) ethyl hydroxyethyl cellulose (EHEC) on the drying stress evolution of $\mathrm{CaCO}_{3}$-polymer, pure $\mathrm{CaCO}_{3}$, and pure polymer films. The addition of soluble polymers induces a substantial increase in both the maximum and residual drying stresses observed for $\mathrm{CaCO}_{3}$-polymer films relative to the pure $\mathrm{CaCO}_{3}$ films, which we largely attribute to the shrinkage that occurs in polymer-rich regions. Based on the drying stress behavior of the pure polymer films, the magnitude of the induced stresses observed in the $\mathrm{CaCO}_{3}$-polymer films could be related to the glass transition temperature and the Young's modulus of the polymer species. We have also explored the effects of plasticizer and surfactant addition on the drying stress evolution of CMC-based films with and without $\mathrm{CaCO}_{3}$, and their mechanisms for drying stress reduction are discussed.

\section{Materials and methods}

\subsection{Materials}

Precipitated $\mathrm{CaCO}_{3}$ particles (Albaglos L PCC, Specialty Minerals, USA) were obtained from the manufacturer as a dry powder (see Fig. 1) with a number mean particle size of $0.84 \mu \mathrm{m}$ with $90 \%$ of the particles finer than $1.5 \mu \mathrm{m}$, as determined by light scattering (Mastersizer 2000, Malvern Instruments). The specific surface area of the $\mathrm{CaCO}_{3}$ powder is $\sim 4.0 \mathrm{~m}^{2} / \mathrm{g}$, as determined by nitrogen gas adsorption (Model ASAP 2400, Micrometrics). X-ray diffraction shows that the $\mathrm{CaCO}_{3}$ powder consists of calcite; no aragonite or other oxides could be found. Sodium polyacrylate (NaPA, Fluka, $M_{\mathrm{w}} \sim 5.1 \mathrm{~kg} / \mathrm{mol}$ ) was used as dispersant. Four different water-soluble polymers were investigated: CMC (Aldrich, $M_{\mathrm{w}} \sim 90 \mathrm{~kg} / \mathrm{mol}, \rho=1.59 \mathrm{~g} / \mathrm{cm}^{3}$ ), EHEC (Bermocoll E 230 FQ, Akzo Nobel Surface Chemistry AB, Sweden, $\rho=1.12 \mathrm{~g} / \mathrm{cm}^{3}$ ), PVA (Aldrich, $M_{\mathrm{w}} \sim$ $31-50 \mathrm{~kg} / \mathrm{mol}, 98-99 \%$ hydrolyzed, $\left.\rho=1.27 \mathrm{~g} / \mathrm{cm}^{3}\right)$, and ASE (Sterocoll HT, BASF, Ludwigshafen, Germany, $M_{\mathrm{w}} \sim$ $\left.4500 \mathrm{~kg} / \mathrm{mol}, \rho=1.05 \mathrm{~g} / \mathrm{cm}^{3}\right)$. The other organic additives studied include: (1) glycerol (Merck, $\rho=1.26 \mathrm{~g} / \mathrm{cm}^{3}$ ), (2) sodium dodecyl sulfate (SDS, Aldrich), and (3) polyoxyethylene 10 lauryl ether $\left(\mathrm{C}_{12} \mathrm{E}_{10}\right.$, Sigma). All additives were used as-received, without further purification. The chemical structure for several of these species are shown in Fig. 2.

\subsection{Suspension and solution preparation}

$\mathrm{CaCO}_{3}$ suspensions $(\phi=0.21)$ were prepared by dispersing the $\mathrm{CaCO}_{3}$ powder in deionized water with $\mathrm{NaPA}$ $\left(\mathrm{NaPA} / \mathrm{CaCO}_{3}=0.003\right)$, followed by mechanical stirring at $500 \mathrm{rpm}$ for $15 \mathrm{~min}$. Their $\mathrm{pH}$ was then adjusted to 9 and they were stirred for another $60 \mathrm{~min}$ at $1000 \mathrm{rpm}$. Finally, each suspension was ultrasonicated for 1 min with a $1 \mathrm{~s}$ on/off

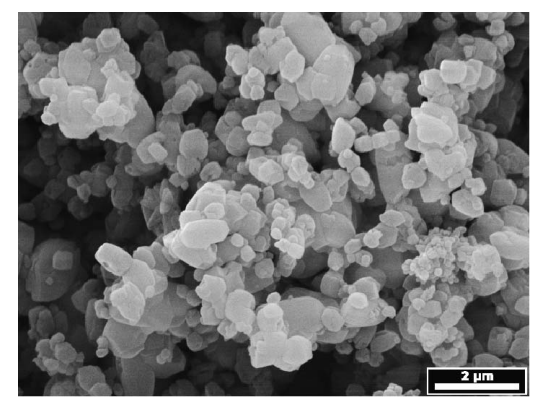

Fig. 1. SEM micrograph of the calcium carbonate powder. 
$\mathrm{CMC}$

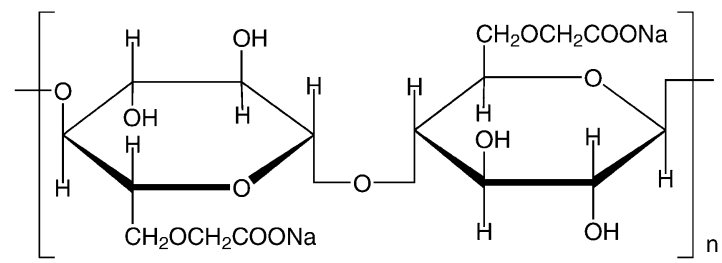

EHEC

PVA
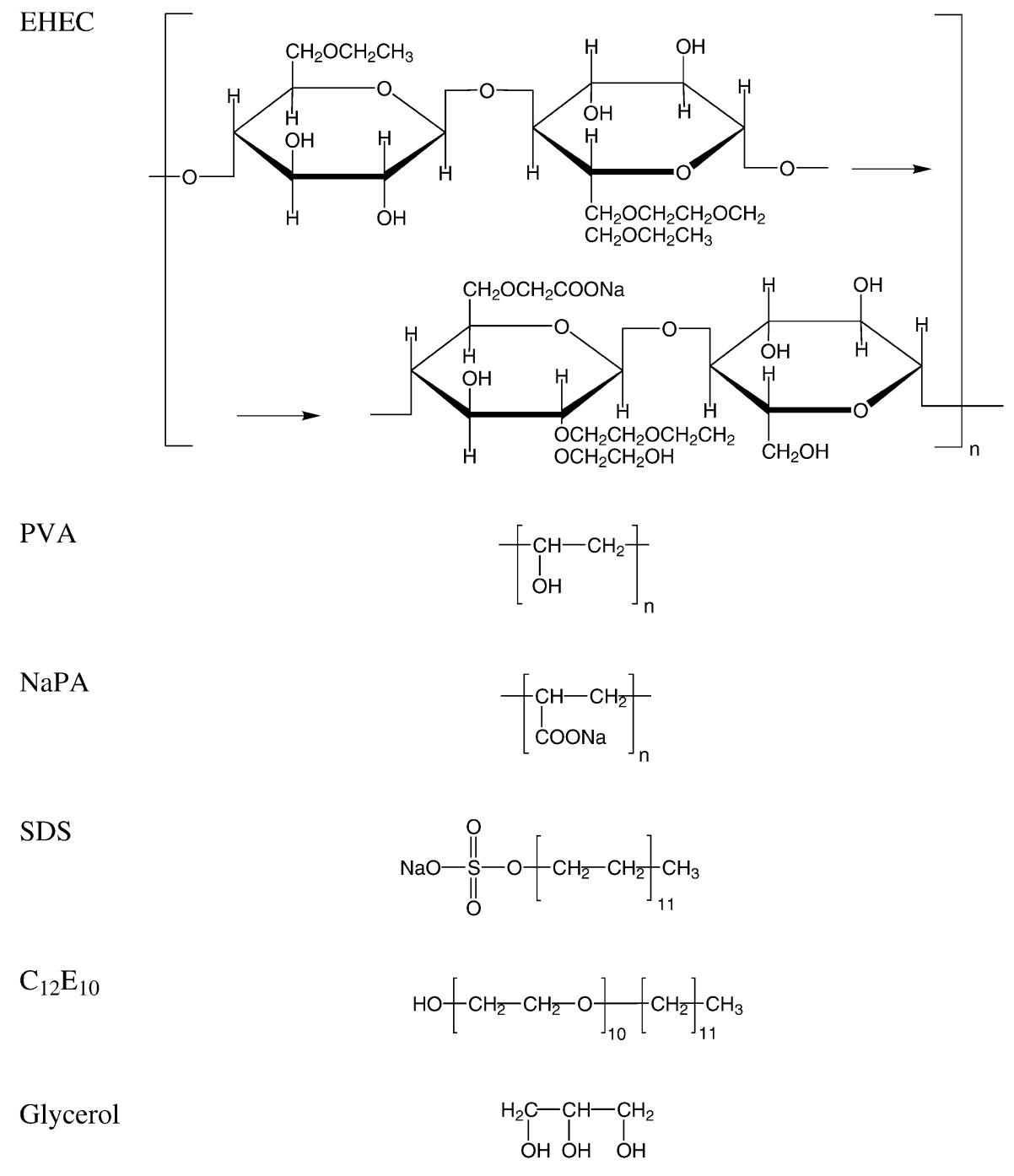

Fig. 2. The chemical structure of the organic additives.

pulse using an ultrasonic horn (Sonics Vibracell VC750, Sonics \& Materials Inc., Newton, CT, USA) and then magnetically stirred for a period of up to $6 \mathrm{~h}$.

$\mathrm{CaCO}_{3}$ suspensions containing soluble organic species were prepared with a polymer/ $\mathrm{CaCO}_{3}$ ratio of 0.01 by weight and a ratio of the small organic additives to the polymer of $1: 3$ by weight. The organic additives were added as a solution to the $\mathrm{CaCO}_{3}$ suspensions, followed by stirring at $500 \mathrm{rpm}$ for $15 \mathrm{~min}$. The $\mathrm{pH}$ was adjusted to 9 and the suspensions were then stirred for another $60 \mathrm{~min}$ at $1000 \mathrm{rpm}$. Finally, each suspension was ultrasonicated for 1 min with a $1 \mathrm{~s}$ on/off pulse using an ultrasonic horn and magnetically stirred for a period of up to $6 \mathrm{~h}$.
Pure polymer solutions (3-5 wt \% polymer) and polymer solutions with either plasticizing or surfactant species were also prepared, where the ratio between these organic species and the polymer was 1:3 (by weight).

\subsection{Drying stress measurements}

The stress histories of the coatings were measured in situ during drying using the cantilever deflection technique. A brief description of the technique is given below and more detailed information can be found elsewhere $[9,17$, 18]. The measurement technique relates the end deflection of a clamped stainless steel substrate to the stress developed 
in an attached coating as it dries. The end deflection was measured using an optical ensemble consisting of a $1 \mathrm{~mW}$ helium laser (Uniphase, Model 1103), a position-sensitive photodiode (UDT Sensors, No. DL-10), an array of mirrors and a data acquisition computer. The steel substrate was positioned beneath a small doctor blade and the suspension was deposited onto the substrate with a syringe. This assembly was then moved beneath the doctor blade at a constant speed of $1 \mathrm{~cm} / \mathrm{s}$ to create a coating of the desired initial thickness (240-520 $\mu \mathrm{m}$, unless otherwise specified). A final film thickness of $\sim 100 \mu \mathrm{m}$ was obtained for each particulate-based coating, and a final film thickness of $\sim 7-20 \mu \mathrm{m}$ was obtained for the pure polymer-based coatings.

This device has an environmental chamber that allows for both humidity (15-70\% RH $\pm 1 \%)$ and temperature $(295-308 \pm 1 \mathrm{~K})$ control. All coatings were dried at a $30 \pm 1 \%$ relative humidity $(\mathrm{RH})$, which varied cyclically between $\sim 29$ and $31 \mathrm{RH} \%$ after film drying ceased, and a temperature of $298 \mathrm{~K}$. The biaxial, in-plane $(x-y)$ stress, $\sigma$, averaged across the coating thickness is related to the substrate deflection by [19]

$\sigma=\frac{d E t_{\mathrm{s}}^{3}}{3 t_{\mathrm{c}} l^{2}\left(t_{\mathrm{s}}+t_{\mathrm{c}}\right)(1-v)}+\frac{d E_{\mathrm{c}}\left(t_{\mathrm{s}}+t_{\mathrm{c}}\right)}{l^{2}\left(1-v_{\mathrm{c}}\right)}$,

where $d, E, E_{\mathrm{c}}, t_{\mathrm{s}}, t_{\mathrm{c}}, l, v$ and $v_{\mathrm{c}}$ are the end deflection, elastic modulus of the substrate, elastic modulus of the coating, substrate thickness, coating thickness, substrate length, Poisson ratio of the substrate and Poisson ratio of the coating, respectively.

If the modulus of the coating is much smaller than the substrate modulus (as is the case for most particulate films on rigid substrates) this second term can be neglected without introducing a significant error ( $\sim 1 \%$ or less) [19]. Therefore, only the first term in Eq. (1) was used for our stress data analysis. The stainless steel substrates used had a thickness of 254-400 $\mu \mathrm{m}$, and clamped dimensions of $50.8 \mathrm{~mm} \times$ $6.35 \mathrm{~mm}$ with the following properties: $E=190 \pm 20 \mathrm{GPa}$, $l=50.8 \mathrm{~mm}$ and $v=0.36$.

Weight loss measurements were simultaneously carried out on duplicate samples in the cantilever stress chamber during the drying stress measurements. The weight loss data was acquired by suspending the coated substrate from a bottom loading balance (Mettler Toledo, Model AG204).

The $T_{\mathrm{g}}$ value for EHEC was determined by differential scanning calorimeter (Mettler Toledo DSC822). Samples were heated at $10^{\circ} \mathrm{C} / \mathrm{min}$. Prior to the DSC measurements, the EHEC powder was stored in vacuum at $70^{\circ} \mathrm{C}$ for $24 \mathrm{~h}$ to minimize the amount of absorbed water.

The Young's modulus for the polymer films $(E)$ was determined by mechanical testing of $0.1-0.25 \mathrm{~mm}$ thick polymer films. These films were cast from solution and stored in a vacuum oven at $23^{\circ} \mathrm{C}$ for $3-5$ days; then cut into $5 \times 40 \mathrm{~mm}^{2}$ test specimens, and mounted in an Instron (Instron universal testing instrument Model 5500) with a gauge length of $15 \mathrm{~mm}$. The specimens were elongated with a strain rate of $25 \mathrm{~mm} / \mathrm{min}$ and the Young's modulus was calculated from the slope of the initial linear region of the stress-strain curve.

The residual water content $\left(\phi_{\mathrm{r}}\right)$ in the polymer films that have equilibrated at $30 \%$ relative humidity and a temperature of $25^{\circ} \mathrm{C}$ for a period of at least 6 days was determined from the weight loss when the polymer films were put into a vacuum oven at $50^{\circ} \mathrm{C}$ for a period of $2-3$ days.

\section{Results and discussion}

\section{1. $\mathrm{CaCO}_{3}$ films}

The stress evolution during drying of films formed from a $\mathrm{CaCO}_{3}$ suspension (Fig. 3) exhibits behavior typical of granular films $[6,10]$. As these data have been previously reported, [9] we only summarize the key features to provide background for evaluating the effect of soluble polymer, plasticizer, and surfactant additions.

Initially, the $\mathrm{CaCO}_{3}$ films exhibit a rapid rise in stress to a maximum value ( $\left.\sigma_{\max }=0.37 \mathrm{MPa}\right)$ followed by a rapid relaxation to a nearly stress-free state. During initial drying there is a negligible stress build-up, the particulate film is supersaturated with liquid and its consolidation is governed solely by the liquid evaporation rate. Eventually, the volume fraction of particles is sufficiently high to enable the particle network to withstand further consolidation. It is possible to estimate the particle volume fraction simply from the weight loss and we find that the stress peak occurs at a particle volume fraction between 40 and 45 vol\% for the investigated $\mathrm{CaCO}_{3}$ suspensions. Beyond this point, liquid menisci form and begin to recede into the particle network and the particle volume can no longer be estimated in this simple fashion due to the development of open pores within the film. The resulting capillary pressure exerts a compressive stress on the

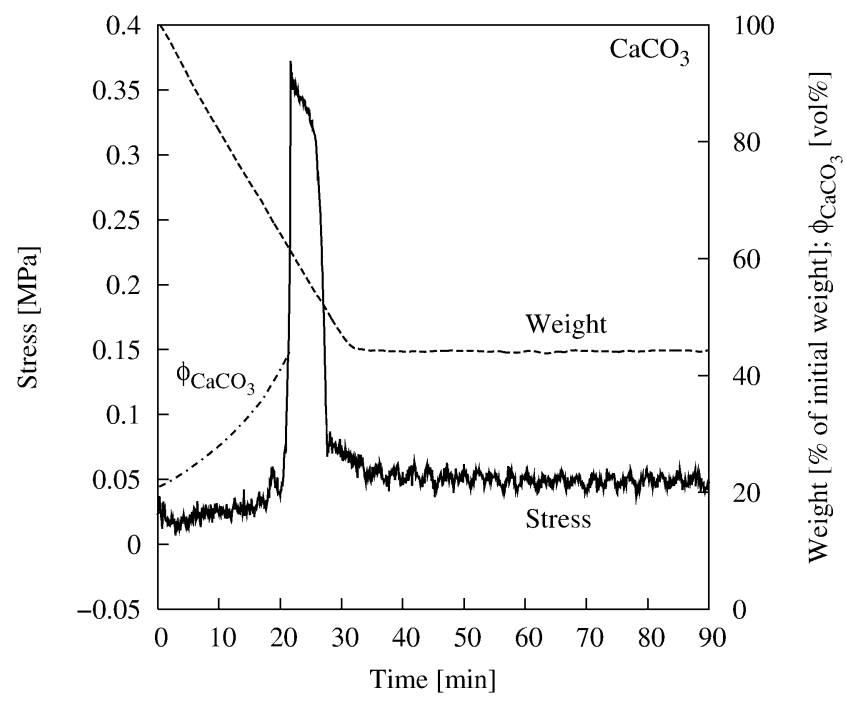

Fig. 3. The drying stress evolution, weight loss profile and the corresponding volume fraction of $\mathrm{CaCO}_{3}$ particles as a function of time for a calcium carbonate film. 
particle network [20]. Upon further evaporation, the stress relaxes quickly attaining a nearly stress-free state. Weight loss measurements (see Fig. 3) reveal that the constant rate period of evaporation extends well beyond the maximum drying stress, i.e. after liquid-vapor interface has receded into the particulate film.

It is possible to calculate the capillary pressure in the film by using the Young-Laplace equation [21]

$P_{\text {cap }}=\frac{2 \gamma}{r_{\mathrm{p}}}$,

where $P_{\text {cap }}, \gamma$ and $r_{\mathrm{p}}$ are the capillary pressure, surface tension and the pore radius, respectively. Since the tortuous capillary pores within the particle network have little in common with cylindrical tubes, an equivalent pore radius can be estimated by using the hydraulic radius, $r_{\mathrm{h}}$, described by [22]

$r_{\mathrm{h}}=\frac{2(1-\phi)}{\phi \rho_{\mathrm{S}} S}$

where $\phi, \rho_{\mathrm{s}}$ and $S$ are the particle volume fraction, density of the solid phase and the specific surface area of the particles, respectively. By using a value for the specific surface area of $S=4.0 \mathrm{~m}^{2} / \mathrm{g}$, we estimate the capillary pressure to be $P_{\text {cap }}=0.55 \mathrm{MPa}$, which is in reasonable agreement with the experimental data $\left(\sigma_{\max }=0.37 \mathrm{MPa}\right)$. Renormalization of drying stress measurements on calcium carbonate suspensions recently reported by Laudone et al. $[15,16]$ also yield maximum in-plane drying stresses on the order of $\sigma_{\max } \approx 0.22-0.27 \mathrm{MPa}$, which is in good agreement with our results.

\subsection{Polymer films}

We have studied the stress evolution of films cast from pure polymer solutions to better understand how the physical properties of the polymer control the magnitude of the observed maximum and residual drying stresses. Please note that the use of a relatively concentrated polymer solution (3-5 wt $\%)$ is needed to yield a final coating thickness that produces a measurable stress response. Fig. 4 shows that the stress initially builds in pure polymer films when their water content reaches $\sim 20-40 \%$ of its initial value coinciding with a decrease in the evaporation rate. The drying stress evolution for three of the polymers, CMC, ASE, and EHEC, follow a similar pattern (Figs. $4 \mathrm{a}, 4 \mathrm{~b}$, and $4 \mathrm{c}$ ) with a relatively strong stress rise followed by little stress relaxation and a stress oscillation that is slowly decreasing in magnitude with time. The magnitude of their maximum drying stress varies significantly, with $\sigma_{\max }$ of $\sim 17,12$ and $3 \mathrm{MPa}$ for the CMC, ASE and EHEC films, respectively. The drying stress evolution for the PVA film differs substantially, as shown in Fig. 4d. In this case, the drying stress increases continuously with time over long periods ( $>8 \mathrm{~h}$ of drying), far beyond the point where evaporation ceases (at $\sim 65 \mathrm{~min}$ ). By extrapolation, we estimate that the stress in the PVA film may ultimately reach a maximum of $\sim 10 \mathrm{MPa}$.
Croll $[23,24]$ carried out one of the first systematic studies on the drying behavior of solvent-cast polymer films. He showed that the magnitude of the residual drying stress in a polymer coating is a function of the Young's modulus $(E)$ of the polymer, the volume fraction of solvent at the point of solidification $\left(\phi_{\mathrm{s}}\right)$, and the volume fraction of solvent in the dry film $\left(\phi_{\mathrm{r}}\right)$, according to:

$\sigma=\frac{E}{1-v} \frac{\phi_{\mathrm{s}}-\phi_{\mathrm{r}}}{3\left(1-\phi_{\mathrm{r}}\right)}$,

where $v$ is the Poisson ratio of the film (estimated 0.33 for the polymers in this study). Please note that the "dry" film may still contain some residual water.

The volume fraction at the point of solidification is usually identified as the solvent concentration at which the glass transition temperature $\left(T_{\mathrm{g}}\right)$ of the polymer-solvent system is equal to the ambient temperature. The solvent concentration at the solidification point can either be determined experimentally $[23,25]$ or by using a model that relates $T_{\mathrm{g}}$ to the water content in the system, e.g., the Gordon-Taylor [26], Fox [27] or the Couchman-Karasz [28] equations. The Gordon-Taylor equation accounts for the plasticizing effect of additives such as water or glycerol according to [26]

$T_{\mathrm{g}}=\frac{w_{1} T_{\mathrm{g} 1}+k w_{2} T_{\mathrm{g} 2}}{w_{1}+k w_{2}}$

with

$k=\frac{\rho_{1} T_{\mathrm{g} 1}}{\rho_{2} T_{\mathrm{g} 2}}$,

where $w, T_{\mathrm{g}}$ and $\rho$ are the weight fraction, glass transition temperature, and the density for the pure components 1 and 2, respectively. The Gordon-Taylor equation (Eq. (3)) is reduced to the more simple Fox equation when the densities of the two components are equal.

These models suggest that it is the glass transition temperature that has a decisive influence on the stress development during drying because $T_{\mathrm{g}}$ controls the shrinkage of the polymer film beyond the solidification point; a polymer with a high $T_{\mathrm{g}}$ will contain more solvent at the solidification point than a polymer with a low $T_{\mathrm{g}}$ and thus shrink more. The glass transition temperature for the polymers used in this study was obtained from literature except for EHEC were we used DSC to estimate $T_{\mathrm{g}}$ (see Table 1). We find that CMC possesses a substantially larger $T_{\mathrm{g}}(=391 \mathrm{~K})$ than the other polymers, whose $T_{\mathrm{g}}$ values range between 348 and $358 \mathrm{~K}$. This suggests that the CMC film should experience the largest shrinkage beyond the solidification point, where the stress rise occurs. Indeed, comparing the stress profiles for these different polymers in Fig. 4 reveals that the stress rise in the CMC film occurs at a water content of about $40 \%$, which is substantially higher than that observed for the other polymer films.

The magnitude of the drying stress is also determined by the stiffness of the polymer, i.e. the Young's modulus $(E)$. The Young's modulus for the polymers was determined from 

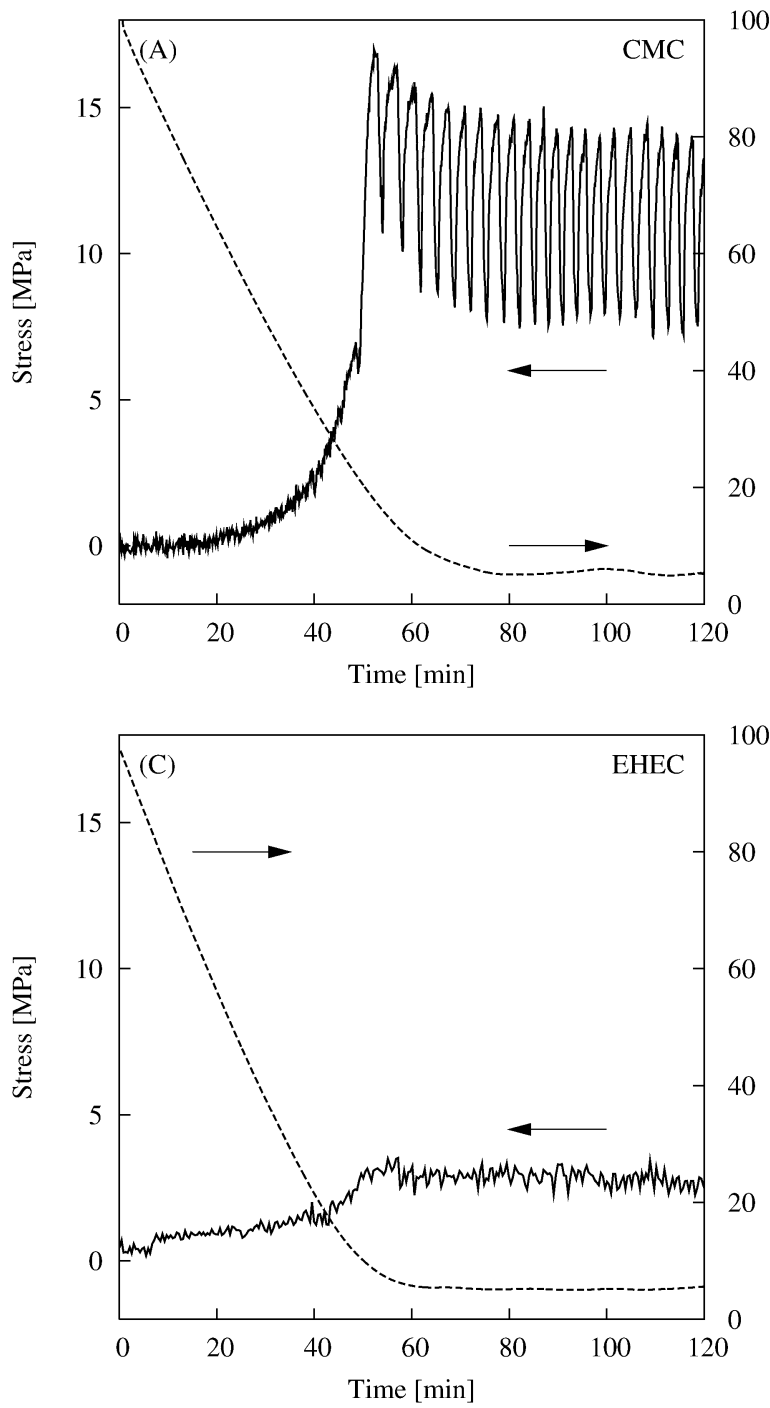
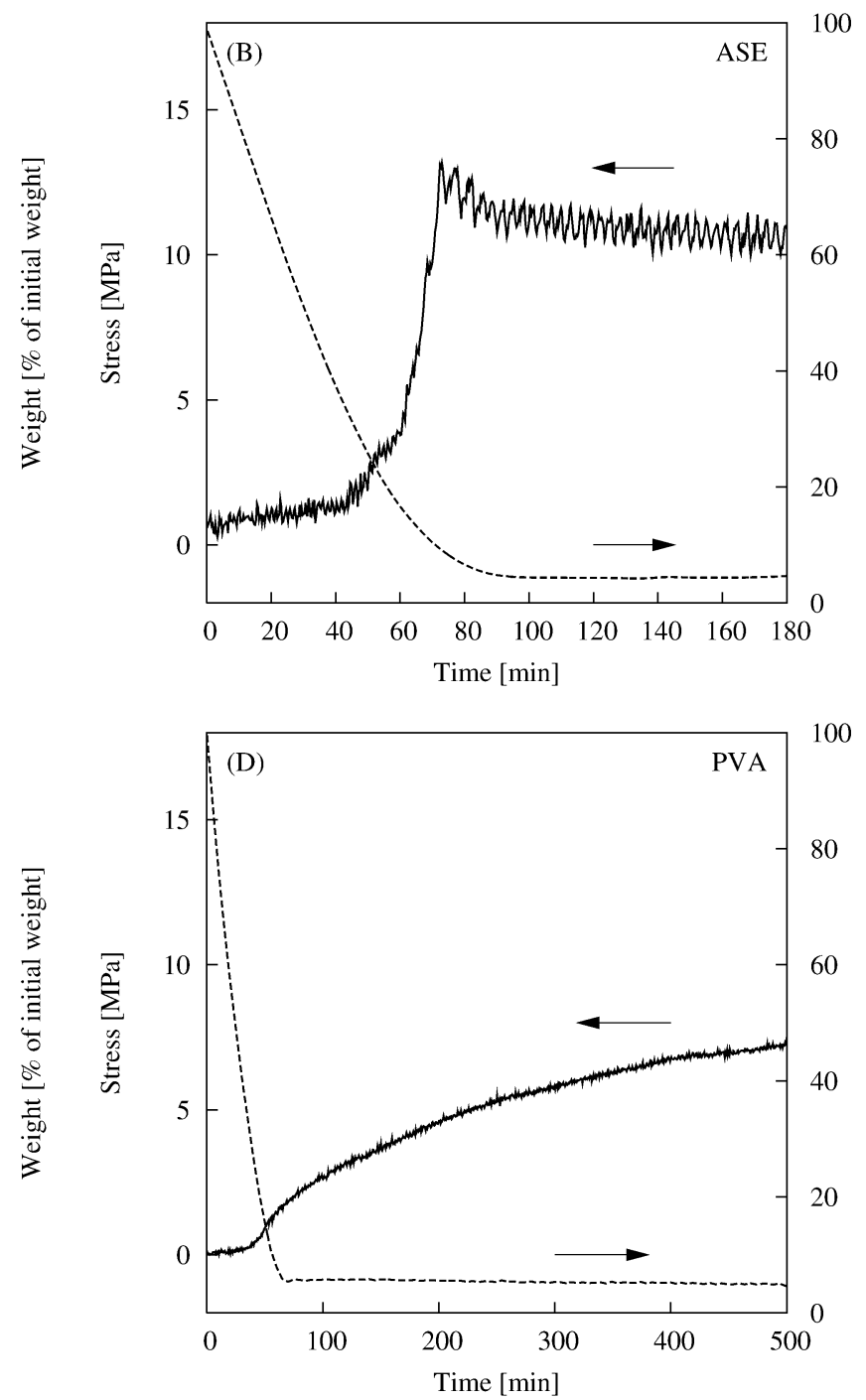

Fig. 4. The drying stress evolution and weight loss profile as a function of time for (A) CMC, (B) ASE, (C) EHEC and (D) PVA films cast from aqueous polymer solutions.

Table 1

Physical properties and drying stress behavior of polymer films

\begin{tabular}{lllllcl}
\hline Component & $\begin{array}{l}T_{\mathrm{g}} \\
(\mathrm{K})\end{array}$ & $\begin{array}{l}E \\
(\mathrm{GPa})\end{array}$ & $\phi_{\mathrm{S}}$ & $\phi_{\mathrm{r}}$ & $\begin{array}{l}\sigma_{\max } \\
(\mathrm{MPa})\end{array}$ & $\begin{array}{l}\sigma_{\mathrm{Gordon}-T a y o r} \\
(\mathrm{MPa})\end{array}$ \\
\hline CMC & $391^{\mathrm{a}}$ & 3.5 & 0.166 & 0.117 & 17 & 78 \\
ASE & $348^{\mathrm{b}}$ & $2.4^{\mathrm{b}}$ & 0.107 & 0.0680 & 12 & 50 \\
PVA & $358^{\mathrm{c}}$ & 2.3 & 0.123 & 0.0515 & $\sim 10$ & 86 \\
EHEC $^{\text {CMC-glycerol }}{ }^{\mathrm{d}}$ & 350 & 0.51 & 0.111 & 0.0349 & 3 & 20 \\
CMC & & 2.6 & & \multicolumn{5}{c}{4.5} \\
\hline
\end{tabular}

${ }^{a}$ Estimated from Picker [34] using the Fox equation.

b Data supplied by the manufacturer.

c From Marten [35].

d The glycerol/CMC ratio is $1: 3$.

the initial linear region of the stress-strain curve when thin polymer films were elongated in a universal testing machine. We estimated $E$ to be 3.5, 2.4, 2.3 and $0.51 \mathrm{GPa}$ for the CMC, ASE, PVA and EHEC films, respectively. Table 1 summarizes the physical properties of the polymers together with the measured maximum stress of the polymer films. CMC films, which have the highest $T_{\mathrm{g}}$ and $E$, also exhibited the largest maximum stress $\left(\sigma_{\max }=17 \mathrm{MPa}\right)$, while EHEC films displayed the lowest stress $\left(\sigma_{\max }=3 \mathrm{MPa}\right)$, as expected, given its low $T_{\mathrm{g}}$ and $E$ values compared to other films.

One can estimate the maximum drying stress in these polymer films using Eqs. (2)-(4). We calculated values that were from $\sim 4$ to 8 times higher than those observed experimentally (Table 1). Such differences may be attributed to several factors. First, small errors in $T_{\mathrm{g}}$ can have a large effect on $\phi_{\mathrm{s}}$ and thus the maximum stress. Second, the polymers studied are water-soluble and their corresponding films typically contained 5-10\% water after drying under ambient conditions. Since water serves as a plasticizer, with a $T_{\mathrm{g}}$ of $136 \mathrm{~K}$ [29], we expect the polymeric intermolecular attractions, and hence Young's modulus, to be weakened compared to the polymer films that were dried in vacuum before mechanical testing. Finally, the amorphous polymers 


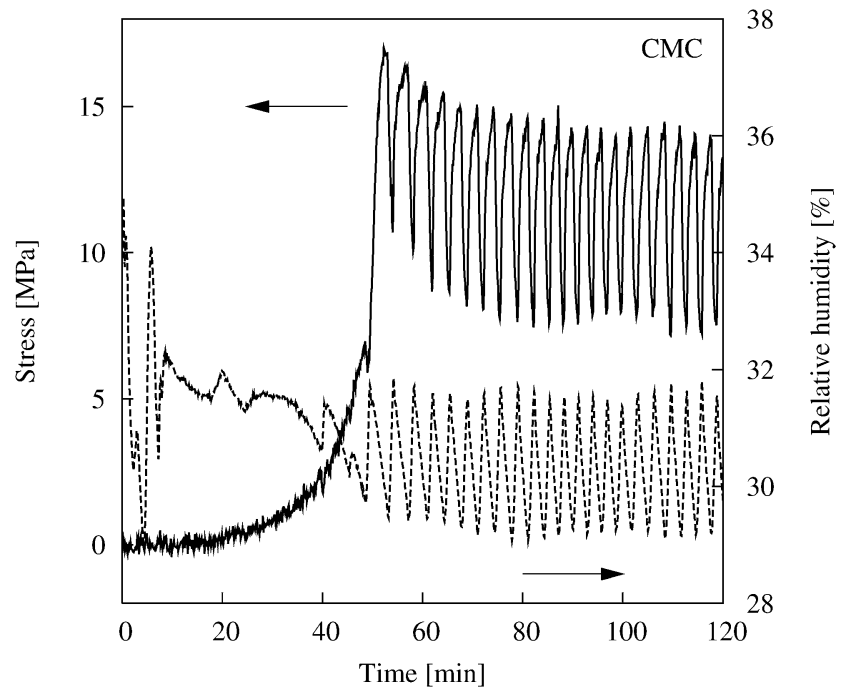

Fig. 5. The drying stress evolution and relative humidity profile as a function of time for a pure CMC film.

are viscoelastic materials, i.e., their mechanical properties exhibit time-dependent behavior. Thus, the effective elastic modulus at the relatively slow deformation induced by drying may be significantly lower than the elastic modulus measured during mechanical testing.

PVA is a semicrystalline polymer, and it has previously been shown that its degree of crystallinity increases as a function of time [30], even at very low water content. This would result in a slow change in modulus and volume as a function of time, which may explain why the stress in the PVA film (Fig. 4c) increases far beyond the point where evaporation ceases.

The importance of volumetric expansion and contraction on stress evolution in polymeric coatings is further supported by how stress in the CMC film varies with the relative humidity, as shown in Fig. 5. We find that the CMC film, and to a lesser degree the ASE, EHEC and PVA films (see Fig. 4), exhibit an oscillatory variation in stress at the residual stress plateau where the frequency of the stress variation can be related to variations in relative humidity in the drying chamber. The uptake and loss of water of these hygroscopic polymer films will affect the volume fraction of water in the film $\left(\phi_{\mathrm{r}}\right)$, thereby resulting their respective expansion and contraction, which gives rise to large fluctuations in stress as the relative humidity varies cyclically from $\sim 29$ to $31 \%$.

\section{3. $\mathrm{CaCO}_{3}$-polymer films}

The drying stress evolution of $\mathrm{CaCO}_{3}$-polymer films is shown in Fig. 6. We find that each binary system displays similar features, as characterized by a relatively small initial stress peak followed by a rapid increase in the stress to a plateau value. The initial stress peak with a magnitude of $\sim 0.2-0.4 \mathrm{MPa}$ occurs at a similar particle volume fraction, $\phi=0.4-0.45$, irrespective of the polymeric binder. Both the magnitude of the stress peak and the correspond- ing particle volume fraction are in good agreement with the behavior observed for pure $\mathrm{CaCO}_{3}$ films (Fig. 3). This similarity strongly suggests that the origin of the first stress rise in these binary films stems from the capillary pressure generated by the liquid phase within the particulate film.

As drying proceeds in these $\mathrm{CaCO}_{3}$-polymer films, the relaxation of the capillary-induced stress peak observed for pure $\mathrm{CaCO}_{3}$ films is overcome by a second stress rise. The magnitude of the maximum drying stress depends on polymer composition, with $\sigma_{\max }$ values of $1.5,0.8,0.65$ and $0.45 \mathrm{MPa}$ observed for binary films containing CMC, ASE, PVA and EHEC, respectively. Indeed, these $\sigma_{\max }$ values follow the same order observed for the pure polymer films, i.e., $\mathrm{CMC}>\mathrm{ASE}>\mathrm{PVA}>\mathrm{EHEC}$, which suggests that the second stress rise of the binary particle-polymer films is dominated by the polymeric species.

It is noteworthy that the second stress rise observed for the $\mathrm{CaCO}_{3}$-polymer films occurs when more than $90 \%$ of their initial water content has evaporated. This is far beyond the point when the liquid has receded into the particle network and the maximum capillary forces are exerted. These trends are in good agreement with prior work on stress development in ceramic films containing soluble binders (polymers) [6] and a related study [9] on the drying behavior of binary $\mathrm{CaCO}_{3}-\mathrm{CMC}$ coatings, which have linked the large residual stress to shrinkage of polymer-rich regions within these films. This conjecture is also supported by the stress oscillations observed for $\mathrm{CaCO}_{3}$-polymer films in the residual stress plateau, which we attribute to the swelling and shrinking of the hygroscopic polymer phase as it absorbs and desorbs water, when the relative humidity varies cyclically within the drying chamber (see Fig. 5). We therefore disagree the interpretation proposed by Laudone et al. [15,16] that the large increase in drying stress observed when a water soluble starch binder is added to a calcium carbonate suspensions merely reflects an increase in capillary pressure within the drying film.

It is interesting to note that the magnitude of the maximum stress is substantially lower for the binary particlepolymer films (Fig. 6) compared to equivalent pure polymer films (Fig. 5). The presence of the particle network may limit the total shrinkage, and thus the induced stress, that the polymeric phase can experience compared to the more unrestrictive shrinkage in the pure polymer film. In fact, similar trends were observed in a previous study on solvent-based coatings [6], when the stress levels of pure polymer (PVB) were found to be substantially higher than the stress levels in the particle-polymer films.

\section{4. $\mathrm{CaCO}_{3}$-polymer-small organic molecule films}

The dominating effect of soluble polymeric species on the drying stress evolution of $\mathrm{CaCO}_{3}$-based films motivated us to explore the influence of other low-molecular weight additives on both pure polymer and $\mathrm{CaCO}_{3}$-polymer films. The drying stress profile and weight loss behavior for a CMC 

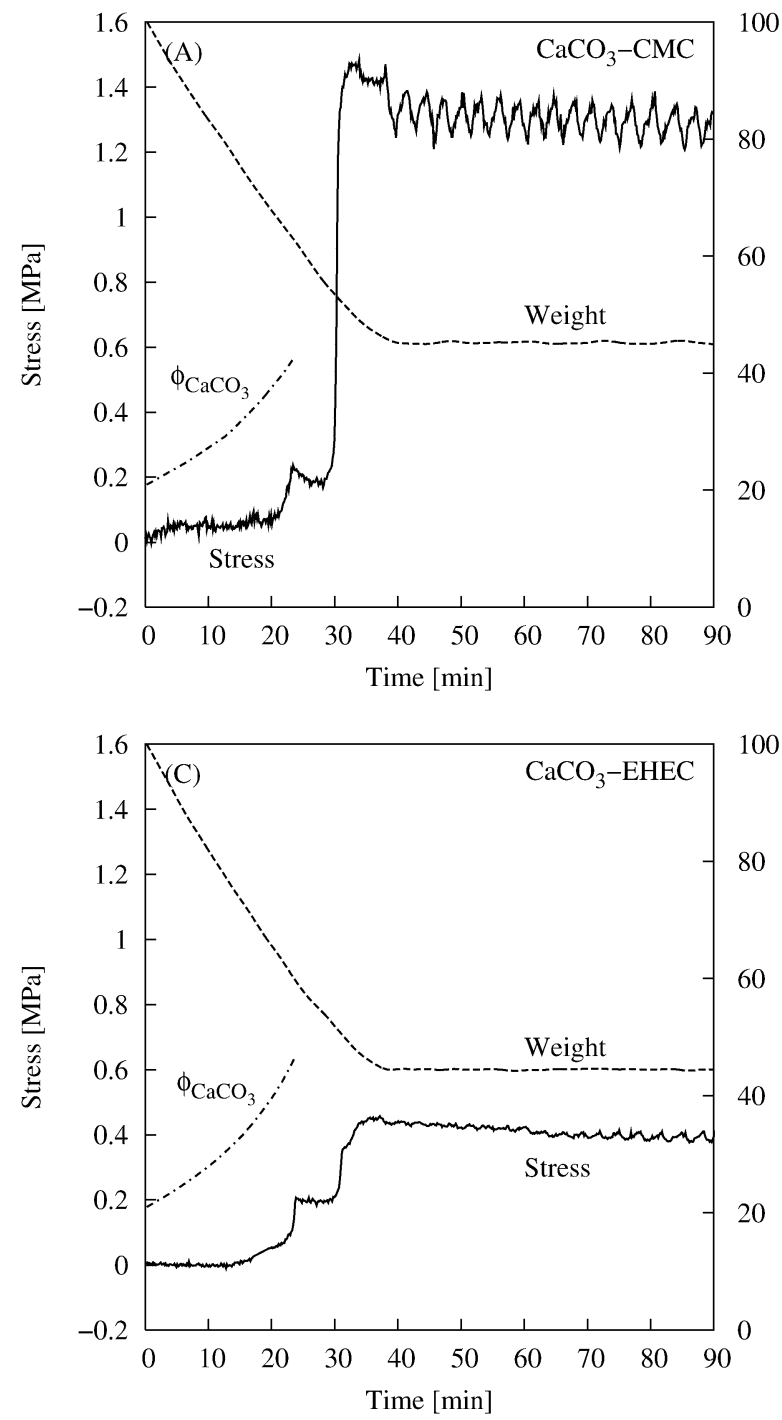

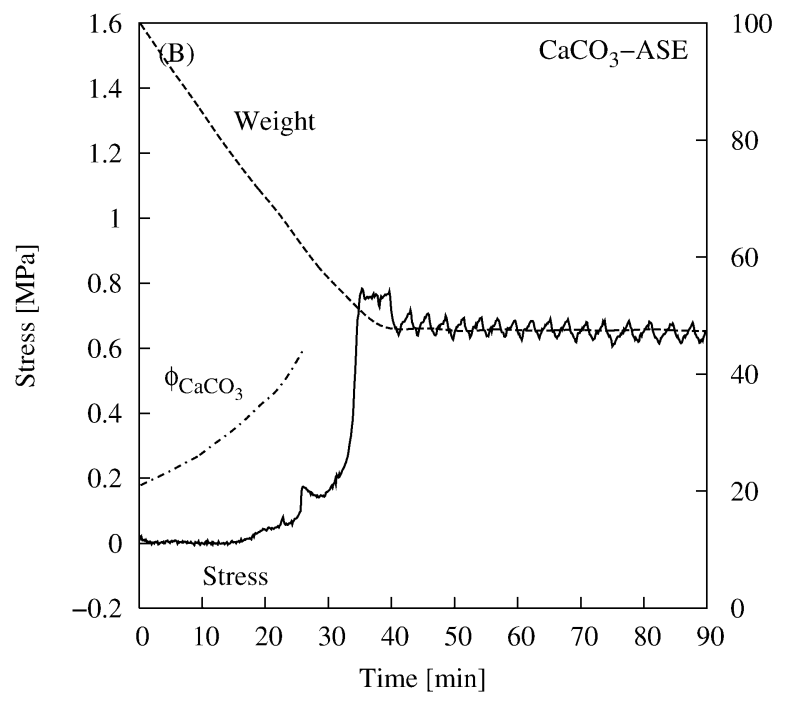

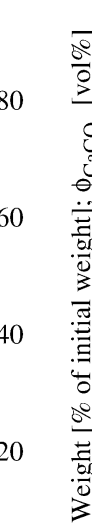

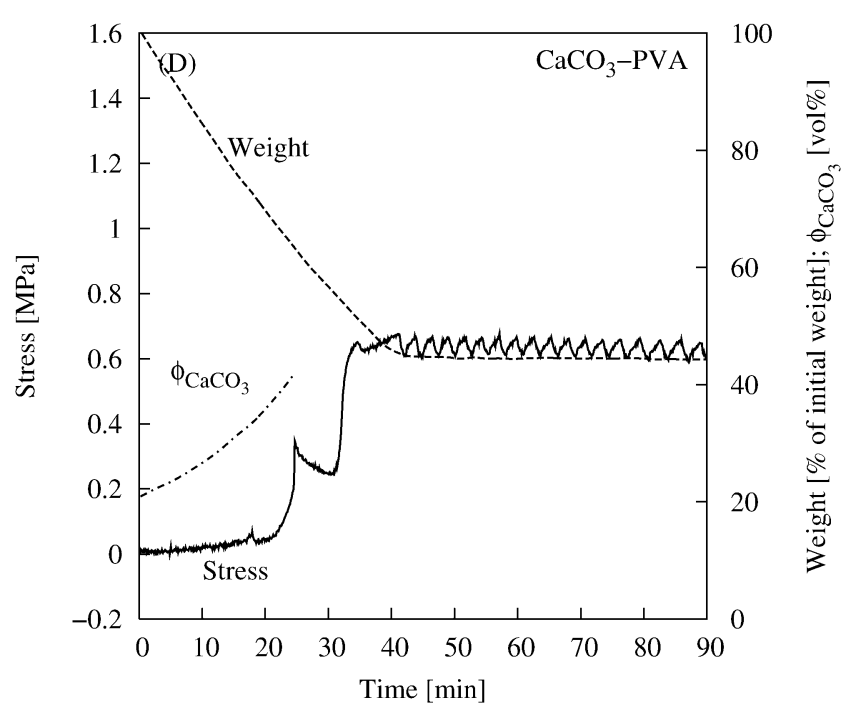

Fig. 6. The drying stress evolution, weight loss profile and the corresponding volume fraction of $\mathrm{CaCO}_{3}$ particles as a function of time for calcium carbonate-polymer films (A) CMC, (B) ASE, (C) EHEC or (D) PVA.

film containing glycerol, an anionic surfactant (SDS), or a non-ionic surfactant $\left(\mathrm{C}_{12} \mathrm{E}_{10}\right)$ are shown in Fig. 7. In each case, a constant rate period of evaporation was observed for these films until $\sim 80-90 \%$ of the initial water content had evaporated. At this point, analogous to the pure CMC film, their drying stress increased rapidly to a maximum value followed by a modest relaxation. Similar to the pure CMC film (Fig. 4a), the films containing these organic additives also displayed oscillations in stress induced by cyclic changes in relative humidity within the drying chamber. The addition of glycerol results in a significant decrease in the maximum drying stress from $17 \mathrm{MPa}$ for the pure CMC film to $\sim 4.5 \mathrm{MPa}$ for the CMC-glycerol film. This stress reduction is mainly attributed to the plasticizing effect of the glycerol species, which reduces the film $T_{\mathrm{g}}$ to $290 \mathrm{~K}[29,31]$ as estimated by the Gordon-Taylor equation. We found that the Young's modulus, $E$, also decreased slightly from $3.5 \mathrm{GPa}$ for the pure CMC film to $2.6 \mathrm{GPa}$ for the CMC-glycerol film.
The addition of anionic or non-ionic surfactants has only a modest effect on the drying stress evolution of CMC films, as reflected by a decrease of $\sigma_{\max } \sim 12$ to $\sim 10 \mathrm{MPa}$ for those containing SDS and $\mathrm{C}_{12} \mathrm{E}_{10}$, respectively. These additives are of interest, because they are normally present in a paper coating formulations that contain surfactant-stabilized latex binder. One interesting observation from our work is that the relatively thick CMC-surfactant films used in the determination of the Young's modulus, turned opaque during drying, while the pure CMC and CMC-glycerol films remained transparent throughout the drying process. The film opacity may indicate that the CMC and surfactant species phase separated during film formation. Vaessen et al. [32] recently reported that the drying stresses were reduced in the polymer films that experience phase separation, as compared to those that remain as a single phase throughout the drying process. Polymer-surfactant incompatibilities also provide a driving force for migration towards interfaces [33], which can adversely affect the adhesive, gloss, and printing prop- 

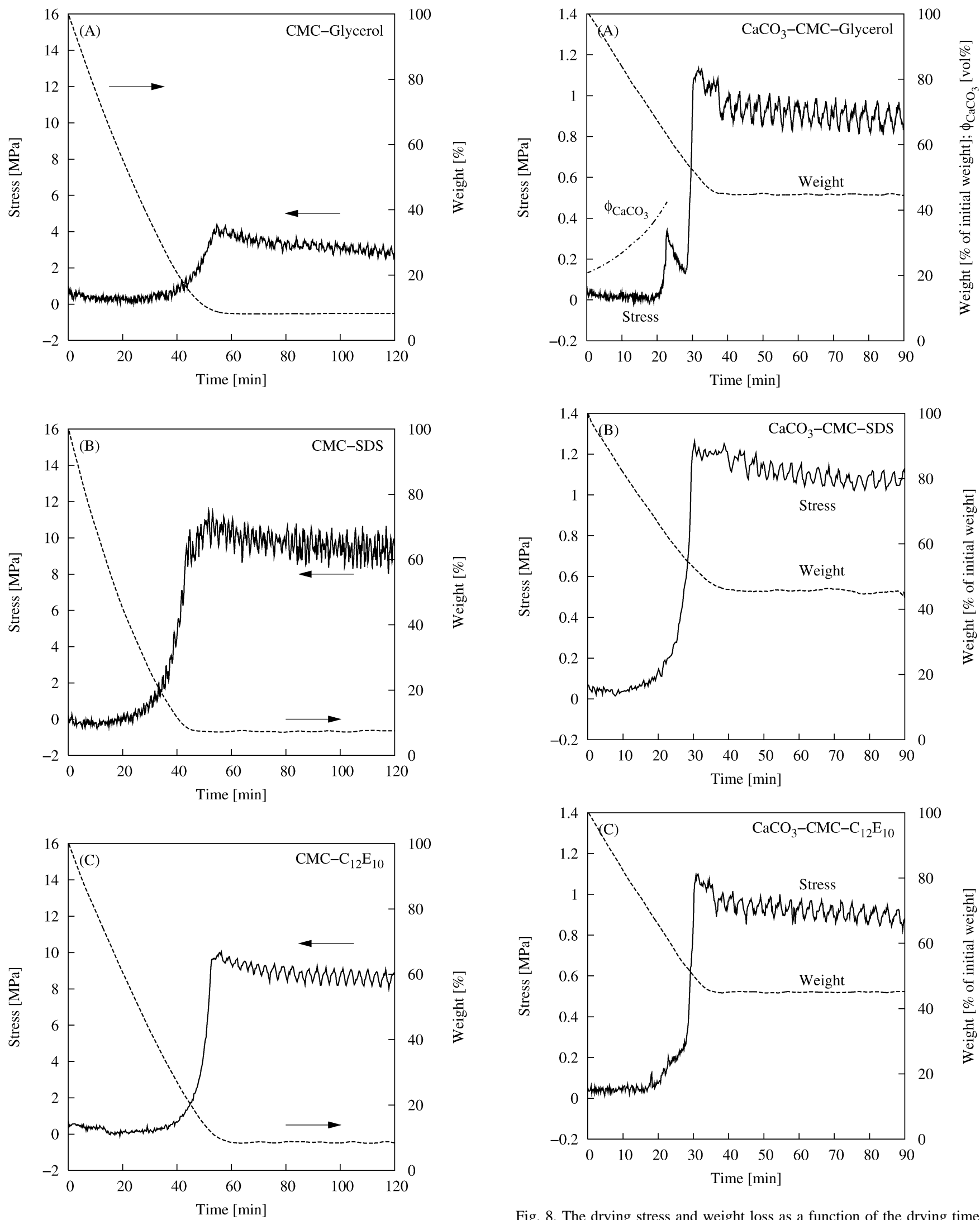

Fig. 8. The drying stress and weight loss as a function of the drying time for the ternary films containing calcium carbonate particles, CMC and the plasticizers: (A) glycerol, (B) SDS or (C) $\mathrm{C}_{12} \mathrm{E}_{10}$, respectively. The corresponding particle volume fraction is also include for figure a where a capillary induced stress peak can be identified.

Fig. 7. The drying stress evolution and weight loss profile as a function of time for CMC films containing (A) glycerol, (B) SDS or (C) $\mathrm{C}_{12} \mathrm{E}_{10}$, respectively. (Note: the $\mathrm{CMC} /$ plasticizer ratio is 3:1.) 
erties of the coating. It is therefore important to tailor these interactions to obtain homogeneous films without significant phase separation and migration.

The drying stress evolution and weight loss profiles of $\mathrm{CaCO}_{3}-\mathrm{CMC}$ films that contain additional organic species (i.e., glycerol, SDS or $\mathrm{C}_{12} \mathrm{E}_{10}$ ) are shown in Fig. 8. The presence of these smaller organic species leads to a slight reduction in the maximum drying stress relative to the $\mathrm{CaCO}_{3}-$ CMC films. However, their initial stress rise differs considerably between ternary films that contain glycerol or a surfactant. Only the $\mathrm{CaCO}_{3}-\mathrm{CMC}-$ glycerol film exhibited a distinct capillary-induced stress peak during the initial stage of drying. In sharp contrast, the $\mathrm{CaCO}_{3}-\mathrm{CMC}-$ surfactant films displayed a smooth increase in the drying stress up to their respective plateau stress values. Such observations suggest that although small organic species can alter the drying stress evolution observed for granular films containing soluble polymers, the origin of their effects differs. For glycerol additions, the drying stress is reduced by its ability to plasticize the polymer phase thereby altering its physical properties (e.g., $T_{\mathrm{g}}$ and $E$ ). In contrast, surfactant additions reduce the surface tension of the liquid phase, thereby suppressing the initial stress rise related to the capillary pressure exerted on the particulate network.

\section{Summary and conclusions}

We have studied how the physical properties of watersoluble polymers and small organic molecules, such as plasticizers and surfactants, influence the drying stress evolution of $\mathrm{CaCO}_{3}$-based coatings using a cantilever deflection technique. We found that pure $\mathrm{CaCO}_{3}$ films exhibited a drying stress evolution that was characteristic of granular films, consisting of a sharp stress rise induced by capillary forces followed by a rapid stress relaxation to a nearly stress-free state. The addition of soluble polymer to these films resulted in a two-stage, drying stress evolution process, where the initial stress rise stems from capillary effects due to the particle network and the second, larger stress rise occurs due to solidification and shrinkage of polymer-rich regions within the granular films. Measurements on the drying stress evolution for the corresponding pure polymer films established a clear correlation between the magnitude of residual stress in both the polymer and $\mathrm{CaCO}_{3}$-polymer films and the physical properties of the polymer phase, such as its glass transition temperature and Young's modulus. Finally, the addition of small organic molecules led a modest reduction in residual stress for both $\mathrm{CMC}-$ and $\mathrm{CaCO}_{3}-\mathrm{CMC}$ films. The addition of glycerol, a plasticizer, reduced the film drying stress by altering the polymer properties (e.g., its glass transition temperature), whereas surfactant additions lowered the surface tension of the liquid phase thereby reducing the capillary pressure exerted on the particulate network during drying.

\section{Acknowledgments}

The authors are grateful to Dr. Nigel Sanders of Specialty Minerals for providing the calcium carbonate powder, and to Dr. Norbert Willenbacher of BASF for determining the modulus and $T_{\mathrm{g}}$ for the ASE.

This work is a part of the Surface Treatment Research Programme at Karlstad University. P.W. and L.B. would like to acknowledge the financial support of the Swedish Pulp and Paper Research Foundation, the Foundation for Knowledge and Competence Development, and the Swedish Agency for Innovation Systems (VINNOVA).

J.A.L. would like to acknowledge the US Department of Energy, Division of Materials Sciences under Award No. DEFG02-91ER45439, through the Frederick Seitz Materials Research Laboratory at the University of Illinois at Urbana-Champaign.

\section{References}

[1] M. Karlsson (Ed.), Papermaking Part 2, Drying, Papermaking Science and Technology, vol. 9, Fapet Oy, Helsinki, Finland, 2000.

[2] P. Heikkilä, P. Rajala, in: E. Lehtinen (Ed.), Drying of Paper Coatings and Drying Equipment, Fapet Oy, Helsinki, Finland, 2000.

[3] C. Petersen, C. Heldmann, D. Johannsmann, Langmuir 15 (1999) 7745.

[4] D.Y. Perera, J. Coat. Technol. 56 (1984) 111.

[5] G.N. Howatt, R.G. Breckenridge, J.M. Brownlow, J. Am. Ceram. Soc. 30 (1947) 237.

[6] J.A. Lewis, K.A. Blackman, A.L. Ogden, J.A. Payne, L.F. Francis, J. Am. Ceram. Soc. 79 (1996) 3225.

[7] E.D. Cohen, E.B. Gutoff, Modern Coating and Drying Technology, VCH, New York, 1992.

[8] E.B. Gutoff, E.D. Cohen, Coating and Drying Defects: Troubleshooting Operating Problems, Wiley, New York, 1995.

[9] P. Wedin, C.J. Martinez, J.A. Lewis, J. Daicic, L. Bergström, J. Colloid Interface Sci. 272 (2004) 1.

[10] R.C. Chiu, M.J. Cima, J. Am. Ceram. Soc. 76 (1993) 2769.

[11] E.R. Dufresne, E.I. Corwin, N.A. Greenblatt, J. Ashmore, D.Y. Wang, A.D. Dinsmore, J.X. Cheng, X.S. Xie, J.W. Hutchinson, D.A. Weitz, Phys. Rev. Lett. 91 (2003).

[12] M.S. Tirumkudulu, W.B. Russel, Langmuir 20 (2004) 2947.

[13] A.F. Routh, W.B. Russel, Langmuir 15 (1999) 7762.

[14] P.A.C. Gane, J.J. Hooper, A. Grunwald, TAPPI J. 80 (1997) 109.

[15] G.M. Laudone, G.P. Matthews, P.A.C. Gane, Coating Shrinkage During Evaporation: Observation, Measurement and Modelling within a Network Structure, in: Proceedings of the 2003 TAPPI 8th Advanced Coating Fundamentals Symposium, 8-10 May 2003, TAPPI Press, Chicago, IL, 2003.

[16] G.M. Laudone, G.P. Matthews, P.A.C. Gane, Ind. Eng. Chem. Res. 43 (2004) 712.

[17] J.A. Payne, A.V. McCormick, L.F. Francis, Rev. Sci. Instrum. 68 (1997) 4564.

[18] J.A. Payne, Stress Evolution in Solidifying Coatings, Ph.D. thesis, University of Minnesota, USA, 1998.

[19] E.M. Corcoran, J. Paint Technol. 41 (1969) 635

[20] G.W. Scherer, J. Am. Ceram. Soc. 73 (1990) 3.

[21] D.F. Evans, H. Wennerström, The Colloidal Domain, Wiley-VCH, New York, 1999.

[22] J.M. Coulson, J.F. Richardsson, Particle Technology and Separation Processes, Pergamon Press, Oxford, 1991.

[23] S.G. Croll, J. Coat. Technol. 51 (1979) 64. 
[24] S.G. Croll, J. Appl. Polym. Sci. 23 (1979) 847.

[25] D. Moran, P.M. Whitmore, in: The Development of Internal Stress in Films of Thermoplastic Polymers Cast from Solution, in: Materials Issues in Art and Archaeology, vol. 4, Materials Research Society, Cancun, Mexico, 1995.

[26] M. Gordon, J.S. Taylor, J. Appl. Chem. 2 (1952) 493.

[27] T.G. Fox, Bull. Am. Phys. Soc. 1 (1956) 123.

[28] P.R. Couchman, F.E. Karasz, Macromolecules 11 (1978) 117.

[29] M. Pouplin, A. Redl, N. Gontard, J. Agric. Food Chem. 47 (1999) 538.

[30] M.O. Ngui, S.K. Mallapragada, J. Polym. Sci. Pol. Phys. 36 (1998) 2771.
[31] R.L. Whistler, J.N. BeMiller (Eds.), Industrial Gums-Polysaccharides and Their Derivatives, third ed., Academic Press, San Diego, CA, 1993.

[32] D.M. Vaessen, A.V. McCormick, L.F. Francis, Polymer 43 (2002) 2267.

[33] V.R. Gundabala, W.B. Zimmerman, A.F. Routh, Langmuir 20 (2004) 8721.

[34] K.M. Picker, J. Therm. Anal. Calorim. 73 (2003) 597.

[35] F.L. Marten, in: H.F. Mark, N.M. Bikales, C.G. Overberger, G. Menges, J.I. Kroschwitz (Eds.), Vinyl Alcohol Polymers, Wiley, New York, 1989 , p. 167 